\title{
ANALISIS KELAYAKAN INVESTASI DALAM RANGKA EKSPANSI (STUDI KASUS PADA PDAM TIRTA SATRIA KABUPATEN BANYUMAS)
}

\author{
Oleh: \\ Nofa Nofiyanti ${ }^{1)}$ \\ Drs. Bambang Sunarko, MM ${ }^{2}$ \\ Ekaningtyas Widiastuti, SE., M.Si ${ }^{3)}$ \\ Email: nofiyanti_nofa@yahoo.com \\ 1) Mahasiswa Fakultas Ekonomi dan Bisnis Universitas Jenderal Soedirman \\ 2), 3) Dosen Fakultas Ekonomi dan Bisnis Universitas Jenderal Soedirman
}

\begin{abstract}
This research study is a case study conducted in PDAM Tirta Satria Kabupaten Banyumas. This research entitled "Invesment Feasibility Analysis in the Context Expansion (Case Study of PDAM Tirta Satria Kabupaten Banyumas)". The objective of this research study is to determine the expansion in fixed assets that will conducted by PDAM Tirta Satria Kabupaten Banyumas feasible in the term of Internal Rate of Return (IRR) and Payback Period methods. Population and sample in this research is PDAM Tirta Satria Kabupaten Banyumas, using boring sampling as a sampling method.

The result of the research showed: the investment in order to expand the addition of fixed assets that will be run by PDAM Tirta Satria Kabupaten Banyumas feasible by considering the results of the analysis Internal Rate of Return method of $21 \%$ which greater than the cost of capital that has been determined of 10\% (IRR>k) and Payback Period method, the investment will show a time for 4 years and 8 months 26 days to capital return on investment so that investment is feasible.
\end{abstract}

Keywords: Feasibility Investment, Cost of Capital, Expansion, Capital Budgeting, Forecasting, Fixed Assets

\section{PENDAHULUAN}

Perkembangan dalam sektor perdagangan, industri, dan jasa yang semakin kompetitif dan semakin ketat membawa perusahaan-perusahaan baik itu perusahaan swasta maupun BUMN dituntut untuk mampu melihat dan mendapatkan peluang yang ada. Persaingan bisnis yang semakin ketat saat ini menjadi tantangan baru bagi perusahaan untuk dapat bertahan dan agar perusahaan dapat tetap eksis atau menjaga keberlangsungan hidup dari perusahaan itu. Banyak perusahaan yang sudah sehat mengambil tindakan untuk menjual sahamnya guna mendapatkan dana yang segar, hal ini umumnya dilakukan oleh perusahaan swasta. Perusahaan BUMN tidak menutup kemungkinan dapat melakukan hal yang sama dikarenakan kebijakan pemerintah walau perusahaan dalam kondisi yang baik.

Adanya kebijakan pemerintah tersebut akan menimbulkan keuntungan maupun kerugian bagi perusahaan. Tidak sedikit perusahan yang mengalami kerugian memilih untuk gulung tikar. Lain halnya dengan perusahaan yang 
mendapatkan keuntungan. Perusahaan yang mendapatkan keuntungan akan mempergunakan hasilnya untuk banyak hal, diantaranya untuk kegiatan investasi modal. Agar perusahaan dapat terus menjalankan kegiatan operasinya diperlukan adanya investasi bagi perusahaan.Semakin banyak investasi yang didapatkan oleh perusahaan maka kemampuan perusahaan dalam menjalankan kegiatan operasinya semakin besar pula.

Investasi perusahaan bisa dalam bentuk pembelian peralatan, pembuatan proyek baru maupun ekspansi. Seperti yang kita ketahui dengan melakukan investasi tersebut perusahaan menginginkan tingkat pengembalian investasi yang tinggi daripada yang perusahaan harapkan guna kesejahteraan stakeholders perusahaan. Untuk menanggapi masalah tersebut maka perusahaan memerlukan teknik analisis investasi jangka panjang yang tepat agar perusahaan dapat memperkirakan tingkat pengembalian yang diharapkan perusahaan apakah sesuai dengan ekspektasi dari perusahaan tersebut.

Menurut Haming dan Basalamah (2003:3), kelayakan investasi secara umum dapat diartikan sebagai keputusan mengeluarkan dana pada saat sekarang untuk membeli aktiva riil (tanah, gedung, kendaraan, dan sebagainya) atau aktiva keuangan (saham, obligasi, reksadana, wesel, dan sebagainya) dengan tujuan untuk mendapatkan penghasilan yang lebih besar di masa yang akan datang.

Investasi akan menghasilkan laba yang tinggi jika dilakukan dengan perencanaan yang matang. Apabila dilakukan dengan perencanaan yang kurang matang, maka investasi yang dil- akukan akan menghasilkan suatu kerugian yang sangat besar bagi perusahaan. Hal ini disebabkan sulit untuk menarik investasi yang sudah dikeluarkan apabila terjadi kesalahan perhitungan.Agar dapat menimbang dan memutuskan dengan tepat, maka data dan fakta-fakta yang dibutuhkan harus tersedia bagi para pimpinan yang bertanggung jawab dalam hal tersebut.

Investasi dinilai bagus jika sebuah perusahaan memiliki profiltabilitas yang tinggi. Profitabilitas adalah kemampuan perusahaan memperoleh laba dalam hubungannya dengan penjualan, total aktiva maupun modal sendiri (Sartono, 2001:130). Rasio profitabilitas mengukur keberhasilan manajemen sebagaimana ditunjukkan oleh laba yang dihasilkan oleh penjualan dan investasi.

Oleh karena itu, untuk menanggapi permasalahan di atas maka setiap perusahaan memerlukan adanya penganggaran modal atau yang lebih dikenal dengan capital budgeting. Capital budgeting berfungsi untuk menilai kelayakan investasi yang akan dilakukan perusahaan. Analisis capital budgeting adalah "suatu proses pengambilan keputusan yang dilakukan oleh suatu perusahaan dalam rangka pemilikan atau keperluan akan aktiva tetap". Keputusan tersebut diambil melalui proses evaluasi atau penilaian atas aktiva tetap yang akan dimiliki atau diperlukan tersebut (Halim, 2008:165). Dalam analisis capital budgeting diadakan suatu penilaian kelayakan investasi dengan menggunakan 5 metode yaitu: metode Payback Period (PP), metode NetPresent Value (NPV), metode Profitability Index (PI), metode Internal Rate of Return (IRR), dan metode Average Rate of Return (ARR). 
Tabel 1. Laporan Laba Rugi PDAM Tirta Satria Untuk Tahun Yang Berakhir 31 Desember 2014 (dinyatakan dalam rupiah)

\begin{tabular}{lll}
\hline Keterangan & Tahun 2014 & Tahun 2013 \\
\hline Pendapatan & & \\
Pendapatan Usaha & $31.505 .411 .411,00$ & $29.468 .526 .905,00$ \\
Pendapatan Non Air & $13.583 .499 .053,46$ & $11.123 .467 .368,00$ \\
Jumlah & $45.088 .910 .464,46$ & $40.591 .994 .273,00$ \\
Beban Pokok Usaha & $(15.043 .533 .840,36)$ & $(13.713 .396 .330,73)$ \\
Laba Kotor Usaha & $30.045 .376 .624,10$ & $26.878 .597 .942,27$ \\
Beban Usaha & & \\
Beban Administrasi \& & $23.255 .739 .854,42$ & $19.154 .301 .773,61$ \\
Umum & & \\
Beban Penjualan & $44.721,500,00$ & $33.519 .500,00$ \\
Jumlah & $23.300 .461 .354,42$ & $19.187 .821 .273,61$ \\
Hasil Usaha & $6.744 .915 .269,68$ & $7.690 .776 .668,66$ \\
Pendapatan Lain-lain & $1.203 .902 .187,44$ & $519.638 .140,55$ \\
Beban Lain-lain & $(2.745 .621,73)$ & $(2.637 .723,00)$ \\
Laba (Rugi) Sebelum Pa- & $7.946 .071 .835,39$ & $8.207 .777 .086,21$ \\
jak & & \\
Beban Taksiran Pajak & $(1.935 .807 .000,00)$ & $(2.016 .247 .600,00)$ \\
Laba (Rugi) Setelah Pajak & $\mathbf{6 . 0 1 0 . 2 6 4 . 8 3 5 , 3 9}$ & $\mathbf{6 . 1 9 1 . 5 2 9 . 4 8 6 , 2 1}$ \\
& & \\
\hline
\end{tabular}

Sumber : Laporan Keuangan

Brealey dan Myers dalam Riyanto (2001:11) mengemukakan bahwa setelah dana diinvestasikan untuk membiayai operasi perusahaan dan mampu menghasilkan keuntungan, maka selanjutnya manajer keuangan akan terlibat dalam pengambilan keputusan mengenai berapa bagian dari keuntungan yang akan dibayarkan kepada pemilik perusahaan atau pemberi dana, dan berapa bagian yang akan diinvestasikan kembali untuk membiayai pertumbuhan perusahaan.

PDAM Tirta Satria yang berlokasi di J1 Prof DR Suharso 52 Purwokerto Lor Kabupaten Banyumas merupakan perusahaan yang melakukan usaha pengelolaan air minum dan usaha-usaha lain yang secara langsung maupun tidak langsung berkaitan dengan usaha tersebut, terutama adalah penyediaan dan pelayanan air minum bagi kepentingan umum.

Penelitian ini bertujuan untuk mengetahui kebijakan perusahaan dalam membuat suatu keputusan investasi modal dalam rangka ekspansi dan untuk mengetahui kelayakan rencana investasi yang dilakukan oleh PDAM Tirta Satria berdasarkan analisis capital budgeting.

Silvia Maysaroh (2012) dalam penelitiannya menyimpulkan bahwa teknik capital budgeting yang digunakan untuk menilai kelayakan investasi aktiva tetap dinyatakan layak pada perusahaan yang diteliti. Hidyat dan Widijawati 
(2007) menyatakan bahwa analisis investasi pengembangan dalam hubungannya dengan tingkat pengembalian, risiko, dan sumber pendanaan di perusahaan yang diteliti dinyatakan layak. Teknik penganggaran modal juga diterapkan oleh Dedy N Baramuli (2009) dalam rangka ekspansi di dalam penelitiannya dan disarankan untuk perusahaan tersebut menjalankan ekspansi dengan mempertimbangkan fungsi manajemen perusahaan.

Berdasarkan latar belakang tersebut, terlihat bahwa analisis capital budgeting sangat penting bagi keberlangsungan kegiatan operasi suatu perusahaan.Oleh karena itu maka perlu dilakukan penelitian tentang "Analisis Kelayakan Investasi Dalam Rangka Ekspansi pada PDAM Tirta Satria Kabupaten Banyumas".

\section{TELAAH PUSTAKA DAN PENGEMBANGAN HIPOTESIS}

\section{Pengertian Investasi}

Menurut Simamora (2002:298) investasi adalah "nilai moneter aktiva yang diserahkan oleh perusahaan untuk memperoleh aktiva jangka panjang". Sedangkan menurut Halim (2005:3) "investasi pada hakekatnya merupakan penempatan sejumlah dana pada saat ini dengan harapan untuk memperoleh keuntungan dimasa yang akan datang". Investasi dapat didefinisikan sebagai penanaman modal terhadap asset perusahaan dalam jangka waktu panjang dan yang nantinya akan menghasilkan laba yang diharapkan.

\section{Biaya Modal (Cost of Capital)}

Biaya modal adalah biaya yang harus ditanggung oleh perusahaan karena menggunakan sumber dana tertentu. Setiap sumber dana baik itu modal sendiri maupun pinjaman mempunyai biaya modal.Menurut Mulyadi ( 2001: 329) terdapat dua pengertian biaya modal yaitu:

a) Biaya modal khusus (specific cost of capital) yaitu biaya yang berhubungan dengan sumber pembelanjaan tertentu pada saat tertentu.

b) Biaya modal rata-rata (average cost of capital) yaitu rata-rata tertimbang dari berbagai biaya modal khusus.

Untuk menggunakan metode biaya modal rata-rata ini perlu ditaksir terlebih dulu biaya modal dari masing-masing sumber dana, yang adalah sebagai berikut (Suad Husnan dan Suwarsono Muhammad, 2000) :
a) Biaya Modal Sendiri
b) Biaya Hutang (Cost of Debt)
c) Biaya Saham Preferen

\section{Definisi Capital Budgeting}

Menurut Halim (2008:165) capital budgeting adalah "suatu proses pengambilan keputusan yang dilakukan oleh perusahaan dalam rangka pemilikan atau keperluan akan aktiva tetap". Sedangkan menurut Warsono (2003:163) penganggaran modal dapat diartikan sebagai "proses pengambilan keputusan investasi yang berbentuk aktiva tetap untuk jangka panjang".Secara garis besar, capital budgeting merupakan proses yang digunakan untuk pengambilan suatu keputusan investasi modal dan untu mengetahui pengembalian dana 
tersebut dalam jangka waktu lebih dari satu tahun atau investasi jangka panjang.

\section{Ekspansi}

Menurut Bambang Riyanto (2008:301) ekspansi merupakan perluasan modal, baik perluasan modal kerja saja, atau modal kerja dan modal tetap yang digunakan secara terus menerus di dalam perusahaan.Sedangkan menurut Alex S.Nitisemito (2004:142) mengemukakan bahwa ekspansi adalah suatu tindakan yang dilakukan oleh perusahaan untuk memperbesar perusahaan dari ukuran yang lebih kecil menjadi ukuran yang lebih besar karena permintaan yang makin bertambah terhadap barang-barang atau jasa-jasanya.

\section{Aktiva Tetap}

Dana yang akan ditanamkan dalam aktiva tetap sama halnya seperti dana yang diinvestasikan dalam aktiva lancar namun perputaran dana yang tertanam dalam kedua aktiva itu berbeda, yaitu investasi dalam aktiva lancar diharapkan akan dapat diterima kembali dalam waktu dekat dan secara sekaligus, yaitu dalam waktu satu hari, satu minggu atau paling lama satu tahun. Sebaliknya investasi dalam mesin, bangunan-bangunan, kendaraan dan lain sebagainya, dana yang tertanam didalamnya akan diterima kembali keseluruhannya oleh perusahaan dalam waktu beberapa tahun, dan kembalinya secara berangsur-angsur melalui depresiasi. (Riyanto, 2008 : 115).

\section{Peramalan}

Menurut Golden et al. dalam Najmudin (2014:02) peramalan adalah kegiatan memprediksi, memproyeksikan, atau memperkirakan sejumlah peristiwa atau kondisi masa depan yang berada di luar kendali langsung perusahaan dan menyediakan dasar untuk perencanaan manajerial.

\section{Perumusan Hipotesis}

Penelitian ini tidak mengangkat dan merumuskan hipotesis karena penelitian ini bersifat studi kasus yang lebih "menstudi" perspektif. Studi kasus adalah penelitian tentang status subjek penelitian berkenaan dengan suatu fase spesifik atau khas dari keseluruhan personalitas (Sylvia dalam Nazir, 2009:57).

\section{METODE PENELITIAN}

Jenis penelitian dalam penelitian ini adalah penelitian deskriptif dengan pendekatan studi kasus.Penelitian deskriptif merupakan penelitian non hipotesis sehingga langkah penelitiannya tidak memerlukan rumusan hipotesis.Subyek dalam penelitian ini adalah PDAM Tirta Satria yang berlokasi di J1 Prof DR Suharso 52 Purwokerto Lor Kabupaten Banyumas.

Jenis data yang digunakan dalam penelitian ini adalah data primer.Data primer merupakan pengambilan data secara langsung kepada subjek penelitian tanpa melalui pihak ketiga. Data primer yang digunakan merupakan data yang didapatkan dari PDAM Tirta Satria Kabupaten Banyumas adalah informasi laporan keuangan PDAM Tirta Satria Kabupaten Banyumas untuk periode yang berakhir 31 Desember 2013 dan 2014. 


\section{TEKNIK ANALISIS DATA}

Untuk menganalisis permasalahan tersebut peneliti menggunakan metode peramalan (forecasting) dan metode Capital Budgeting sebagai teknik analis data.

1. Metode Simple Average

$\hat{\mathrm{Y}}_{\mathrm{i}(\mathrm{j})}=\frac{\mathrm{Y}_{t(j-1)}+\mathrm{Y}_{i(j-2)}}{k}$

Keterangan:

$\hat{Y}_{i}$ : Ramalan

$\mathrm{Y}_{\mathrm{i}}$ : Data historis

j : Tahun

i : Bulan (berarti $\mathrm{n}=12$ )

$\mathrm{k}: 2$ (minimal 2)

2. Metode Payback period (PP)

$\mathbf{P P}=\frac{\text { Original Investment }}{\text { Cash Flow }} \times 1$ thn

3. Metode Internal Rate of Return (IRR)

Rumusnya sebagai berikut (Suliyanto, 2010:208):

$\sum_{t=0}^{n}\left[\frac{A_{t}}{(1+r)^{t}}\right]=0$

Keterangan :

$\mathrm{r}$ : tingkat bunga yang akan menjadikan PV dari Proceeds sama dengan PV dari capital outlays

At : Cash flow untuk periode $\mathrm{t}$

$\mathrm{n}$ : Periode terakhir dimana cash flow diharapkan

t : Periode waktu

\section{HASIL DAN PEMBAHASAN}

Dari informasi yang diperoleh berdasarkan laporan keuangan PDAM Tirta Satria Kabupaten Banyumas maka langkah selanjutnya adalah menganalisis data investasi yang telah didapatkan.
Asumsi yang digunakan dalam penelitian ini adalah sebagai berikut :

1) Perhitungan besarnya investasi dalam rangka ekspansi penambahan aktiva tetap untuk tahun 2014 adalah sebesar Rp 101,825,902,770.27 diperoleh dari aktiva tetap yang dimiliki oleh perusahaan untuk periode tahun yang berakhir pada 31 Desember 2014.

2) Cost of capital yang digunakan dalam penelitian ini adalah sebesar $10 \%$ dengan menggunakan suku bunga dari bank rekanan PDAM Tirta Satria Kabupaten Banyumas.

3) Metode penyusutan aktiva tetap yang digunakan adalah metode garis lurus sesuai dengan kebijakan akuntansi aktiva tetap PDAM Tirta Satria Kabupaten Banyumas. Sedangkan metode peramalan (forecasting) menggunakan metode simple average. Metode peramalan ini digunakan untuk menghitung net cash in flow yang diperoleh dari laba bersih setelah pajak (EAT) perusahaan pada tahun 2014 dan 2013.

4) Umur investasi yang disyaratkan adalah selama 10 tahun dengan melihat banyaknya (modus) aktiva tetap PDAM Tirta Satria Kabupaten Banyumas yang berumur ekonomis selama 10 tahun (terdapat 13 dari 36 aktiva tetap).

Berikut ini adalah analisis kelayakan investasi pada PDAM Tirta Satria:

1) Metode Simple Average 
Perhitungan Cash In Flow didapatkan dengan cara meramalkan atau melakukan forecasting dengan metode simple average sebagai berikut :

$$
\begin{aligned}
& \text { Cash In Flow } \left.=\hat{\mathrm{Y}}_{\mathrm{i}(\mathrm{j})}\right) \\
& =\frac{Y_{t(j-1)}+Y_{i(j-2)}}{k} \\
& =\frac{\text { EAT tahun 2013+EAT tahun } 2014}{2} \\
& =\frac{6 \cdot 191 \cdot 529.486,21+6 \cdot 010 \cdot 264.835,39}{2} \\
& =R p 6.100 .897 \cdot 160,79
\end{aligned}
$$

Sedangkan untuk perhitungan proceeds didapatkan dari menjumlahkan laba bersih setelah pajak (EAT) dengan depresiasi.

$$
\begin{aligned}
& \text { Proceeds = EAT + Depresiasi } \\
& =12 \cdot 201.794 \cdot 321,57+9 \cdot 327.450 .629,02 \\
& =\operatorname{Rp} 21 \cdot 529 \cdot 244.950,59
\end{aligned}
$$

\section{2) Analisis Internal Rate of Return}

Dengan data yang ada di atas kemudian mencari apakah investasi yang akan dilaksanakan layak atau tidak dengan menggunakan analisis capital budgeting. Cost of capital yang digunakan adalah sebesar $10 \%$.

\section{3) Analisis Payback Period (PP)}

Untuk menghitung ekspektasi atau harapan pengembalian investasi yang akan dijalankan dapat dihitung dengan cara sebagai berikut :

$$
\begin{aligned}
\text { PP } & =\frac{\text { Investasi kas bersih }}{\text { Aliran kas masuk bersih tahunan }} \\
& =\frac{101.825 .902 .707,27}{21.519 .244 .950,59} \\
& =4,729
\end{aligned}
$$

Untuk menghitung sisa hari dilakukan perhitungan sebagai berikut :

$$
\begin{aligned}
& 0,729 \times 365=266,085 \text { hari } \\
& 266,085: 30 \text { hari } \quad=8,86 \text { bulan } \\
& 0,86 \times 30 \text { hari } \quad=25,8 \text { hari } \\
& \text { dibulatkan men- } \\
& \text { jadi } 26 \text { hari }
\end{aligned}
$$

Berdasarkan perhitungan di atas maka dapat disimpulkan bahwa Payback Period dari investasi tersebut adalah selama 4 tahun 8 bulan 26 hari.

\section{KESIMPULAN, IMPLIKASI DAN SARAN}

\section{A. Kesimpulan}

Berdasarkan hasil penelitian dapat disimpulkan bahwa :

1. Investasi dalam rangka ekspansi penambahan aktiva tetap yang akan dijalankan oleh PDAM Tirta Satria Kabupaten Banyumas layak untuk dijalankan dengan mempertimbangkan hasil analisis metode Internal Rate of Return sebesar $21 \%$ yang lebih besar daripada cost of capital yang telah ditentukan yakni sebesar $10 \%$ ( IRR > k ).

2. Metode Payback Period, rencana investasi akan menghasilkan waktu selama 4 tahun 8 bulan 26 hari untuk pengembalian modal yang ditanamkan. Periode waktu yang disyaratkan selama 10 tahun, hal ini berarti bahwa dana yang diinvestasikan sebesar $\mathrm{Rp}$ 101.825.902.707,27 sudah akan dapat diperoleh dalam waktu yang kurang dari waktu yang disyaratkan (lebih cepat) sehingga 
investasi ini layak untuk dijalankan.

\section{B. Implikasi}

Berdasarkan hasil penelitian maka dapat diimplementasikan :

1. Bagi manajemen PDAM Tirta Satria Kabupaten Banyumas sebaiknya tetap menjalankan rencana investasi yang akan dilaksanakan karena berdasarkan pada hasil perhitungan dengan menggunakan teknik analisis capital budgeting menunjukkan bahwa investasi yang direncanakan layak untuk dijalankan dengan tetap memperhatikan adanya kemungkinan aspekaspek lain yang terlibat di dalam rencana investasi tersebut.

2. Bagi pemerintah sebaiknya memberikan dukungan lebih kepada perusahaan milik negara dalam mengelola usahanya baik perusahaan barang maupun jasa agar tidak tersaingi dengan perusahaan asing yang bergerak dalam bidang yang sama dengan tetap memperhatikan kebijakankebijakan pemerintah dalam kaitannya dengan perusahaan BUMN itu sendiri.

3. Bagi dunia pendidikan menambah referensi ilmu manajemententang analisis capital budgeting yang dapat digunakan untuk membantu perusahaan dalam menganalisis suatu investasi yang akan dijalankan apakah investasi yang akan dilaksanakan akan memberikan tingkat pengembalian yang diharapkan oleh perusahaan dan stakeholders perusahaan tersebut.

\section{Keterbatasan Penelitian}

Dalam sebuah penelitian tidak lepas dari adanya suatu keterbatasan, adapun keterbatasan dalam penelitian ini adalah :

1. Peneliti hanya menggunakan data Laporan Keuangan untuk periode tahun yang berakhir 2014.

2. Untuk menganalisis rencana investasi yang akan dijalankan hanya menggunakan dua metode saja yakni metode Internal Rate of Return dan Payback Period.

3. Teknik peramalan untuk cash flow menggunakan teknik simple average, hal ini dikarenakan peneliti belum bisa memastikan besarnya laba maupun pendapatan perusahaan di masa yang akan datang selain itu dikarenakan laba perusahaan yang menjadi subjek penelitian berfluktuasi.

\section{Saran Untuk Penelitian Selanjut- nya}

Dalam penelitian ini masih banyak keterbatasan dan ketidaksempurnaan, untuk itu peneliti memberikan saran untuk penelitian selanjutnya untuk menyempurnakan ilmu tentang analisis capital budgeting.

1. Tidak hanya menggunakan periode laporan keuangan satu tahun namun bisa 3-5 tahun dan menggunakan laporan keuangan yang terbaru.

2. Untuk melakukan analisis capital budgeting bisa menggunakan metode analisis selain Internal Rate of Return dan Payback Period, metode yang bisa 
digunakan antara lain Accounting Rate of Return (ARR), Net Present Value (NPV), Profitability Index (PI) karena metode dapat digunakan sebagai acuan atau pedoman kelayakan suatu investasi.

3. Teknik peramalan yang digunakan bisa menggunakan regresi linier yang lebih analitik dibandingkan dengan metode simple average atau bisa menggunakan teknik peramalan yang lainnya namun dilihat kembali kondisi perusahaan dan investasi yang akan dijalankan tersebut.

\section{DAFTAR PUSTAKA}

Baramuli, Dedy N. 2009. Analisis Penganggaran Modal Dalam Rangka Ekspansi Pada PT Telkomsel, Tbk. Jurnal Inovasi Manajemen Volume 5 No 2 Agustus 2009.

Halim, Abdul. 2003. Analisis Investasi. Edisi ke-1. Salemba Empat. Jakarta.

Halim, Abdul. 2005. Analisis Investasi. Edisi 2. Salemba Empat. Jakarta.

Halim, Abdul. 2008. Manajemen Keuangan (Dasar Perusahaan Pembelanjaan). BPFE.Yogyakarta.

Haming, M., dan Basalamah. 2003. Studi Kelayakan Investasi. PPM. Jakarta.

Hidayat, Lukman dan Eti Widijawati. 2007. Analisis Investasi Pengembangan Dalam Hubungannya
Dengan Tingkat Pengembalian, Risiko, dan Sumber Pendanaan. Jurnal Ilmiah Sekolah Tinggi Ilmu Ekonomi Kesatuan Bogor.

Husnan, Suad. 1996. Manajemen Keuangan Teori dan Penerapan (Keputusan Jangka Pendek).Buku 2. Edisi Ketiga. BPFE.Yogyakarta.

Husnan, Suad dan Suwarsono Muhammad. 2000. Studi Kelayakan Proyek. Unit Penerbit dan Percetakan.Yogyakarta.

Husnan, Suad dan Eny Pudjiastuti. 2006. Dasar-Dasar Manajemen Keuangan. Edisi 5. UPP STIM YKPN. Yogyakarta.

Laporan Keuangan PDAM Tirta Satria untuk tahun yang berakhir 31 Desember 2014.

Mulyadi. 2001. Sistem Akuntansi. Salemba Empat. Jakarta.

Maysaroh, Silvia, dkk. 2010. Penerapan Teknik Capital Budgeting Untuk Menilai Kelayakan Investasi Aktiva Tetap (Studi Kasus pada PT. Pabrik Es Wira Jatim Unit Pabrik Es Kasri Pandaan). Jurnal Fakultas Ilmu Administrasi Universitas Brawijaya.

Najmudin. 2014. Teknik Peramalan Bisnis. Universitas Jenderal Soedirman. Purwokerto.

Nazir, Moh. 2009. Metode Penelitian. Ghalia Indonesia. Bogor.

Nitisemito, S.Alex. 2004. Pembelanjaan Perusahaan. Ghalian Indonesia. Jakarta.

Riyanto, Bambang. 2010. Dasar-dasar Pembelanjaan Perusahaan. Edisi 4.BPFE.Yogyakarta. 


\section{http://jp.feb.unsoed.ac.id}

Riyanto, Bambang. 1995. Dasar-dasar Pembelanjaan Perusahaan. Edisi Ke-empat. Cetakan Pertama. Badan Penerbit Fakultas Ekonomi. Yogyakarta.

Riyanto, Bambang. 2001. Dasar-dasar Pembelanjaan Perusahaan. Badan Penerbit Fakultas Ekonomi. Yogyakarta.

Riyanto, Bambang. 2008. Dasar-dasar Pembelanjaan Perusahaan. GPFE.Yogyakarta.

Sartono, Agus. 2001. Manajemen Keuangan: Teori \& Aplikasi, Cetakan Pertama, Edisi Ke-empat. BPFE.Yogyakarta.

Simamora, H. 2002. Akuntansi Manajemen. UPP AMP YKPN.Jakarta.

Sugiyono, Prof, Dr. 2013. Statistika Untuk Penelitian. Alfabeta. Bandung.

Suliyanto. 2010. Studi Kelayakan Bisnis. Edisi ke-1 .ANDI.Yogyakarta.

Supriyono, R.A. 1987. Konsep Dasar Akuntansi Manajemen dan Proses Perencanaan. BPFE.Yogyakarta.

Syamsuddin, L. 2004. Manajemen Keuangan Perusahaan.PT Raja Grafindo Persada. Jakarta.

Warsono. 2003. Manajemen Perusahaan. Publishing. Malang.

www.bi.go.id 